\title{
Giant-cell pneumonia caused by measles and methotrexate in childhood leukaemia in remission
}

\author{
M J LEWIS, A H CAMERON, K J SHAH, D R PURDHAM, J R MANN
}

British Medical fournal, 1978, 1, 330-331

\section{Summary and conclusions}

Four children who had acute lymphoblastic leukaemia in remission and developed pneumonia were studied. Investigations including electron microscopy and immunofluorescence of lung biopsy material disclosed measles, although there was no clinical evidence of the disease. Despite an identical presentation, two types of illness developed: two children died of giant-cell pneumonia, while the other two developed pneumonia indistinguishable from that associated with methotrexate treatment, recovering when treated with steroids and gammaglobulin.

Measles infection is easily overlooked in the absence of rash. The diagnosis may be suggested by clinical and radiological features and confirmed by specific immunofluorescence staining of lung biopsy tissue.

\section{Introduction}

Measles may run an atypical course in children being treated for leukaemia, ${ }^{1}$ probably because of immunosuppression caused by cytotoxic drugs and radiotherapy. The usual criteria for diagnosis, such as a rash or rise in antibody titre, may be absent, ${ }^{23}$ causing diagnostic difficulty. We describe four such cases in children with acute lymphoblastic leukaemia (ALL) in remission who developed pneumonia. Lung biopsy and specific immunofluorescence staining were useful in making the definitive diagnosis. In two of the cases we found an unrecorded association between measles and a form of pneumonia ascribed to methotrexate.

\section{Case histories}

The four children were in remission of their disease but had pancytopenia when the pneumonia developed. Cases 1-3 were being treated according to the MRC UKALL III protocol, ${ }^{5}$ and case 4 was on a similar regimen.

Case 1-A 3-year-old girl developed a transient erythematous rash, nonproductive cough, and vomiting during treatment week 12 . The cough worsened over the next two weeks, and, despite the absence of clinical findings, chest radiography showed widespread miliary opacities. Cytotoxic treatment was stopped and there was a brief clinical and radiological improvement. A week later she became very ill with fever, cyanosis, tachypnoea, and finger-clubbing. The chest was still clinically clear but an $x$-ray film showed extensive honeycomb changes. Open-lung biopsy showed giant-cell pneumonia. She died the next day of respiratory failure.

Case 2-During the 28th treatment week a 4-year-old girl developed a non-productive cough but no rash. A week later chest radiography showed

\section{Children's Hospital, Birmingham B16 8ET}

M J LEWIS, MRCP, MRCPATH, senior registrar in haematology (present address: Department of Haematology, General Hospital, Birmingham B4 6NH)

A H CAMERON, MD, FRCPATH, consultant pathologist

K J SHAH, MB, FRCR, consultant radiologist

D R PURDHAM, FIMLs, senior chief technician, virology department

J R MANN, MRCP, DCH, honorary consultant clinical haematologist extensive miliary opacities, although the results of clinical examınation were normal. Cytotoxic treatment was stopped, but the following week she developed fever, cyanosis, tachypnoea, and finger-clubbing. One dose of $\bar{\omega}$ pooled gammaglobulin $750 \mathrm{mg}$ was given intramuscularly after open-lung $\widetilde{\mathbb{D}}$ biopsy, which showed giant-cell pneumonia. She died six days later of respiratory failure.

Case 3-A 12-year-old boy developed fever, non-productive cough, and vomiting but no rash during the 18th treatment week. Cytotoxic treatment $\vec{\circ}$ was stopped but two weeks later he was cyanosed and tachypnoeic. Chest $\overrightarrow{\vec{c}}$ signs were absent but $x$-ray examination showed changes similar to those in $\vec{\omega}$ cases 1 and 2 . Open-lung biopsy disclosed extensive pneumonic changes, $\overparen{O}$ histologically with a few multinucleate giant cells. Treatment, which included $\frac{0}{3}$ prednisolone $40 \mathrm{mg} / \mathrm{m}^{2}$ daily, folinic acid, and pooled gammaglobulin $1500 \mathrm{mg}$ intramuscularly, was followed by dramatic clinical improvement $\overrightarrow{.}$ and a normal chest $x$-ray picture within five days. The boy remained well and $\rightarrow$ completed his antileukaemic treatment.

Case 4-During treatment week 34 a 3-year-old girl developed hepatomegaly and pneumonia similar to that in cases 1-3. Lung biopsy was not performed. Treatment with prednisolone $40 \mathrm{mg} / \mathrm{m}^{2}$ and intramuscular pooled gammaglobulin $1250 \mathrm{mg}$ induced rapid clinical recovery; chest $\frac{\mathrm{O}}{\mathrm{T}}$ radiographs were normal within a week, and the hepatomegaly resolved over $\rightarrow$ three months. She continued on antileukaemic treatment and one year later $\rightarrow$ developed bacterial pneumonia. Haemophilus influenzae and influenza type A T virus were grown from throat swabs. As the pneumonia was slow to resolve, $\mathbb{D}$ bronchoscopy was performed: the bronchial aspirate yielded measles virus. The pneumonia cleared with antibiotics and physiotherapy, and the child completed her antileukaemic treatment.

\section{INVESTIGATIONS}

Radiology-All cases showed similar radiological appearances initially - namely, perihilar and widespread peribronchial fine nodular $\overline{0}$ opacities, which were more noticeable in the zones near the bases. In the two children who died a diffuse honeycomb pattern with increased $\stackrel{\mathbb{Q}}{\mathscr{Q}}$ interstitial markings and tiny translucencies developed; blotchy areas $\overrightarrow{\overrightarrow{\hat{O}}}$ of consolidation appeared terminally. The radiological details of $\frac{0}{3}$ cases 1-3 are reported elsewhere. ${ }^{6}$

Histopathology-Lung biopsy in cases 1-3 showed extensive alveolar exudate of mononuclear cells. In several areas the ducts and air sacs contained coarse strands of fibrin. Multinucleate giant cells, which were numerous in cases 1 and 2 but few in case 3, had up to 30 nuclei. Many eosinophilic inclusions were seen in the nuclei and cytoplasm in cases 1 and 2 . In general, the lining epithelium of the air sacs was 3 . hyperplastic and seemed to participate in the formation of giant cells. Eosinophils were not prevalent. Electron microscopy in cases 1 and $\frac{\circ}{3}$ 3 confirmed the hyperplasia of granular pneumonocytes. At high magnifications the nuclear inclusions of the giant cells in case 1 had a structure consistent with that of the paramyxovirus group, which $N$ includes measles. There were no viral inclusions in case 3.

Virology-No patient had a history of recent contact with measles. $\frac{7}{0}$ Measles virus was cultured in case 1 (from lung biopsy and postmortem lung tissue), case 2 (postmortem lung tissue), and, one year $\mathrm{O}$ after the initial illness, case 4 (bronchial aspirate). Measles virus was not grown in case 3 but there was measles immunofluorescence in the $\sigma$ lung biopsy tissue; a stronger reaction was elicited in biopsy tissue from cases 1 and 2. Complement-fixing antibodies to measles were absent from the serum. Immunoglobulin concentrations were normal.

\section{Discussion}

The clinical and radiological features in these cases are not $\stackrel{\mathbb{Q}}{\mathscr{Q}}$ unique to measles, being found in other viral pneumonias and Pneumocystis carinii infection. Nevertheless, even in the absence 8 of rash or a measles contact, measles should be considered in a child receiving immunosuppressive treatment. Direct virus isolation takes many weeks, but rapid results can be obtained by immunofluorescence studies of nasopharyngeal secretions or lung biopsy tissue. Histologically proved giant-cell pneumonia 
caused by measles but without a rash is generally fatal, ' but early diagnosis and stopping cytotoxic treatment may allow some return of immune function. Since the UKALL III regimen was modified ' fewer deaths have occurred during remissions attributable to immunosuppression. Moreover, large doses of pooled gammaglobulin may benefit children with leukaemia who have established measles. ${ }^{1}$

The clinical and radiological features in case 3 together with the response to treatment were consistent with methotrexate pneumonia, which is characterised by fever, cough, dyspnoea and cyanosis, scattered pulmonary opacities in chest $x$-ray films, ${ }^{+}$ and usually a prompt response to steroids. ${ }^{x-16}$ Reported pathological features were also consistent. ${ }^{+11-1+}$ There is no clear relation between this syndrome and methotrexate, however, as some patients improve while still taking the drug ${ }^{4}$ and others do not react to further challenge. ${ }^{x-10}$ Allergy ${ }^{4}$ or a direct toxic reaction" 11 to methotrexate has been blamed; a virus has not previous!y been implicated. Whether the illness in case 3 was due to primary measles infection or an abnormal reaction induced by methotrexate to latent virus is uncertain. The response to steroids implicates methotrexate.

The isolation of measles virus from case 4 one year after the initial episode of pneumonia was unexpected. Since the virus evoked no antibody response, it had possibly remained latent from the original illness. Persistence of measles virus occurs in leukaemic children ${ }^{3}$ and is a feature of measles inclusion-body encephalitis. ${ }^{1 .}$

Our findings suggest that children receiving immuno- suppressive agents and methotrexate and infected by measles virus may develop either fulminating giant-cell pneumonia or a condition indistinguishable from methotrexate pneumonia, which responds to steroids and gammaglobulin. The factors governing the particular response are not clear.

\section{References}

1 Pullan, C R, et al, British Medical fournal, 1976, 1, 1562.

2 Enders, J F, et al, New England fournal of Medicine, 1959, 261, 875.

${ }^{3}$ Mitus, A, et al, New England fournal of Medicine, 1959, 261, 882.

4 Clarysse, A M, et al, fournal of the American Medical Association, 1969, 209, 1861.

${ }^{5}$ McLennan, I C, Peto, J, and Kay, H E M, British fournal of Cancer. In press.

'Shah, K J, et al, Annales de Radiologie, 1977, 20, 79.

' Williams, H E, and Phelan, P D, Respiratory Diseases in Children. Oxford, Blackwell Scientific Publications, 1975.

${ }^{8}$ Robertson, J H, British Medical fournal, 1970, 2, 156.

9 Whitcomb, M, et al, Thorax, 1972, 27, 636.

1" Schwartz, I R, and Kajani, M K, Fournal of the American Medical Association, 1969, 210, 1924.

${ }^{11}$ Filip, D J, et al, Fournal of the American Medical Association, 1971, 216, 881.

12 Goldman, G C, and Moschella, S L, Archives of Dermatology, 1973, 103, 194.

${ }^{13}$ Rawbone, R G, et al, British Medical fournal, 1971, 4, 467.

14 Gutin, P H, et al, Cancer (Philadelphia), 1976, 38, 1529.

${ }^{15}$ Drysdale, H C, et al, fournal of Clinical Pathology, 1976, 29, 865.

\title{
Late treatment of paracetamol poisoning with mercaptamine
}

\author{
JENNIFER M SMITH, W O ROBERTS, SYBIL M HALL, T A WHITE, A A GILBERTSON
}

British Medical fournal, 1978, 1, 331-333

\section{Summary and conclusions}

Forty patients who had taken overdoses of paracetamol were treated with mercaptamine. Twenty-three patients given mercaptamine within 10 hours of poisoning had normal liver function tests at follow-up, and one could not be traced. In 16 patients mecraptamine was begun more than 10 hours after ingestion of paracetamol ("late" mercaptamine). Eight of these patients developed severe liver damage, which in six was moderate or severe before mercaptamine administration. Acute renal failure occurred in two patients; in one other renal function was temporarily severely impaired. At follow-up two patients were not available, and one admitted moribund had died soon after admission. The remaining 13 all had normal liver function tests.

\footnotetext{
General Intensive Therapy Unit, Sefton General Hospital, Liverpool L15 2HE

JENNIFER M SMITH, FFARCS, senior anaesthetic registrar

SYBIL M HALL, BSC, FRIC, principal biochemist

T A WHITE, MSC, FRIC, senior biochemist

A A GILBERTSON, FFARCS, director of unit and consultant anaesthetist

Caernarvonshire and Anglesey General Hospital, Bangor, Gwynedd W O ROBERTS, FFARCS, consultant anaesthetist
}

It is concluded that late mercaptamine is not dangerous and may prevent further liver damage.

\section{Introduction}

Mercaptamine (cysteamine) appears to be highly effective in preventing liver damage after paracetamol poisoning. ${ }^{1-3}$ There is evidence, however, that it may be ineffective ${ }^{3}$ or even harmful ${ }^{4-6}$ if started more than 10 hours after an overdose. Nevertheless, in view of the high mortality rate associated with liver failure due to paracetamol poisoning, we did not feel justified in withholding mercaptamine from patients seen more than 10 hours after they had taken a toxic dose; and we report here the results of treating 16 patients presenting 10-72 hours after the overdose.

\section{Patients and methods}

\section{THE PATIENTS}

We included 51 unselected patients in the study -34 women aged 13-60 (mean 26), and 17 men aged 19-67 (mean 29).

Gastric lavage was performed on all patients admitted from the casualty department and blood was taken for estimating the paracetamol concentration. We gave mercaptamine to 40 patients whose paracetamol concentrations fell on or above the danger line in the graph of Prescott $e t$ al, ${ }^{1}$ extrapolating for those admitted more than 12 hours after taking paracetamol. The others had only general supportive treatment, and all of these recovered uneventfully. The 40 patients treated with mercaptamine were divided into two groups (see table)- 